\title{
A Clinical Study of Retrograde Amnesia
}

\section{Following Accidental Head Injuries}

\author{
Masami Saito and Dai Ohya \\ Department of Neuropsychiatry, Kansai Medical University, Osaka 570 \\ Kizo Sakaguchi \\ Izumigaoka Hospital, Osaka 594 \\ Toru Aoki \\ Ohmi-Hachiman Seijukai Hospital, Shiga 523 \\ Masao Wakeno \\ Wakeno Hospital, Osaka 534 \\ (Received for publication October 9, 1990)
}

Key wards : Retrograde amnesia, Head injury, posttraumatic amnesia, Hypnosis, Psychogenic amnesia

\section{Introduction}

The word "amnesia" usually evokes the image of an auto accident victim who has no memory of the circumstances in which he sustained his injury. Post-traumatic amnesia (PTA), as this type of memory loss is named, involves loss of memory of the accident itself and is usually accompanied by some degree of retrograde amnesia (RA), which is the inability to recall incidents that occurred preceding the onset of the trauma.

It is quite obvious that a patient will have no memory of incidents which occurred during periods of unconsciousness or severe confusion just after an accident. Nevertheless, the memory loss generally includes informations which the patient had registered up to the very moment of the accident. Quite clearly there is a labile phase of information intake, during which a powerful interference, either physiological or psychological, can prevent an experience from being consolidated into the memory system ${ }^{8)}{ }^{16)}$.

The PTA is often a most useful indication of severity, but it should correspond reasonably well with the duration of RA also to be related to the severity of the cerebral concussion. However, the present authors have observed a number of post-traumatic patients with RA, which has convinced us that the decisive factor in RA is neither the location nor the severity of cerebral damage but the personality and the emotional conflict of patient. In this paper the 
authors present clinical observations of those patients and a discussion of the peculiarity and the nature of RA as well as PTA in cases of head injury.

\section{Frequency of Retrograde and Post-Traumatic Amnesia}

During the period 1959 to 1965,847 head injury patients (648 male and 199 female) visited the out-patient clinic of the Department of Neuropsychiatry, Kansai Medical Univerisity Hospital. Of them, 144 were found to have PTA and/or RA when first seen after the injury. The other patients, who did not describe any memory loss, may have been free from amnesia; however, they cannot be assessed accurately since it is not certain that they were checked for amnesia. In April, 1966, department of neurosurgery has been established in our university. Thereafter, patients with post-traumatic disorders have become to visit the new department and to consult us only when psychiatric interview or treatment required. This is why the investigation was interrupted in 1966.

During recuperation, particularly in acute injury, the RA would shrink at a varying rate to a point where memory of subsequent events ceased abruptly, as many investigators have reported. In an acute state the RA, as well as the PTA, was assessed when the patient was fully recovered from any clouding of consciousness. The PTA was measured as the period between injury and subsequent resumption of a normal continuous memory and the RA as the time between injury and the last clear memory. Thus the isolated memory and the lucid interval have been eliminated from the length of amnesia because the patient would not yet have been satisfactorily conscious at that time.

The Table 1 shows the occurrence of RA in 144 cases of PTA. Most RAs with a duration under 30 minutes were for a few moments only. The table clearly indicated that a PTA under one hour was rarely accompanied by RA. As shown in Table 2, the correlation

Table 1 Duration of PTA and RA compared in 144 accidental head injuries

\begin{tabular}{ccccccc}
\hline $\begin{array}{c}\text { Duration } \\
\text { of RA }\end{array}$ & Nil & 1 hour & $\begin{array}{c}\text { Duration of PTA } \\
1 \sim 24 \text { hrs. }\end{array}$ & $1 \sim 7$ days & 7 days up & Total \\
\hline Nil & 0 & 79 & 24 & 8 & 7 & 118 \\
under 30min. & 0 & 5 & 4 & 1 & 2 & 12 \\
$.5 \sim 8$ hrs. & 0 & 0 & 5 & 2 & 0 & 7 \\
$8 \sim 24$ hrs. & 0 & 0 & 0 & 2 & 1 & 3 \\
over 1 day & 0 & 0 & 2 & 1 & 1 & 4 \\
\hline Total & 0 & 84 & 35 & 14 & 11 & 144 \\
\hline
\end{tabular}


coefficient is . 226, which is statistically significant at a level of $99 \%$. However, the coefficient is low enough to ignore actual correlation between PTA and RA. Correlations are not significant in our cases of RA longer than one hour at a level of $95 \%$. They are significant in our cases shorter than one hour and in Russell's cases longer than a half hour at a level of $99 \%$, while the others are all significant at a level of $99.5 \%$. Coefficients bolow 3.0 should be meaningless even if the statistical testings presented so high significance levels as $99 \%$ to $99.5 \%$.

There was no case of RA without PTA when head injury was involved either in Russell's or in our material. Between PTA and RA longer than a half hour in our patients there is no significant correlation at the .10 level. Out of 722 patients with PTA over one hour Russell describes only eleven who did not also have RA; a $98.5 \%$ incidence of RA associated with PTA over ond hour. Such an extraordinarily high incidence is hardly acceptable from our clinical experience, which resulted in a figure of $35.0 \%$. It is not quite clear why there were so many cases of RA in his material as to be unbelievable.

As is well known, RA is easily influenced by the mildest degree of confusion, and a shrinkage of RA during the days following injury is not uncommon. There are many severe cases associated with long PTA in Russell's material as compared with ours. It is possible that Russell measured the RA before there was clinical evidence of maximal recovery of cerebral function, a little bit earlier than he intended, because of the severity and length of dysfunction. Incidentally, the great majority of RAs are of only a few seconds duration in head injury.

Table 2 Correlation coefficients between the durations of PTA and RA calculated from the raw data of the present authors and the published data in Russell's paper.

1. All subjects : Product moment correlation (Pearson's formula)

Rank order correlation (Spearman's formula)

Ours

Russell's

2. Selected subjects :

Russell's $(\mathrm{N}=200)$

3. Partial comparison :

Ours

Shorter than one hour

Longer than one hour

Shorter (rank)

Longer (rank)

Russell's ( $N=200$ )

Shorter than a half hour

Longer than a half hour

$$
r=0.226 \quad(t=2.76>t .895=2.62)
$$

$$
\mathrm{r}=0.363 \quad(\mathrm{t}=4.64>\mathrm{t} .995=2.62)
$$$$
\mathrm{r}=0.493 \quad(\mathrm{t}=18.07>\mathrm{t} .995=2.62)
$$

$$
r=0.403 \quad(t=6.77>t .995=2.62)
$$

$$
\begin{array}{ll}
r=0.261 & (\mathrm{t}=3.17>\mathrm{t} .995=2.62) \\
\mathrm{r}=0.189 & (\mathrm{t}=0.65>\mathrm{t} .995=2.62) \\
\mathrm{r}=0.219 & (\mathrm{t}=2.60>\mathrm{t} .99=2.36) \\
\mathrm{r}=0.390 & (\mathrm{t}=1.40>\mathrm{t} .95=1.66) \\
\mathrm{r}=0.290 & (\mathrm{t}=3.81>\mathrm{t} .995=2.62) \\
\mathrm{r}=0.374 & (\mathrm{t}=2.49>\mathrm{t} .99=2.36)
\end{array}
$$


However, it is difficult to discriminate patients without RA from patients with an extremely short RA associated with PTA. Except in circumstances of exceptionally close attention, there is a certain time lag during which memories are organized and fixed in the brain; a sudden head injury within this time lag prevents the organization necessary for the recording of a memory. This is why the authors have more strictly discriminated RA from an indistinct memory loss due to this failure to record than other investigators have, and also why we have exclusively studied RA over a half hour. Since the incidences of RA over 30 minutes to PTA over one hour are $24.3 \%$ in Russell's and $23.3 \%$ in our experience, this minor difference in criteria of momentary RA between Russell and us appears to be the only possible explanation for the disagreement between the respective results; however, this is not an essential disagreement.

Out of 144 cases of PTA in which the presence of memory loss was recorded in detail, 26 cases had RA as well as PTA. Half of them had the short (mostly momentary) but distinct type of RA while the others had the marked type of RA over one hour. Most of the latter patients were given intensive treatment and made good recovery. The following case observations ilustrate the treatments applied and their results.

\section{Case Observations}

Case 1 : G. A., male, age 25, laundryman, had an auto accident at 6:45p. m., November 3, 1962, and was badly injured. His car, carrying four other passengers, crashed head on with a truck on Route 1. Two weeks later after having fully recovered consciousness, he had an isolated memory of visiting resorts on September 2 and October 29 and no recollection of the subsequent weeks. The PTA had shrunk to 14 days and the RA to two months by December 14, 1963, when he visited our clinic with a complaint of memory disorder.

On examination, he was oriented, alert and a little anxious. A capillary fracture in the right temporal region of the skull was seen on $\mathrm{X}$-ray examination. The resting EEG was normal but a $60 \mathrm{mg}$ intravenous injection of bemegride induced a burst of diffuse spike wave complexes.

Patient S.M., one of the passengers involved in the accident, was sitting next to the driver and was injured more seriously than G. A. A fracture of the mandibullar bone and a capllary fracture of the skull in the middle fossa and in the temporal region were found on $\mathrm{X}$-ray; the EEG examination revealed low amplitude records at rest and atypical spike wave complexes after a 70mg injection of bemegride. He had PTA for 15 days but not RA. The other three passengers, sitting in the rear seat, had neither PTA nor RA.

G. A. was given tentative treatment which attempted to reduce the RA, as well as PTA, 
by increasing the islands of memory in the RA under a hypnotic trance. After repeated attempts, he remembered that he had previously made arrangements with the others for the tour of September, October and November, and recalled other incidents during that period, but could not remember what happened for several hours before the accident. He now has a permanent RA for one day and PTA of 14 days $^{10)}{ }^{11)}$.

Case 2: L.K., male, age 27, white-collar worker, was injured in s head-on collision at a steep curve on Route 13 early in the morning on August 15, 1963. He regained consciousness a few seconds later and was considered quite alert because he was able to converse and to behave sensibly at the police inspection held hours after the accident. After visiting a nearby surgeon to have his lacerated forehead stitched, he reported for work and remained there until 1 p.m., when he went home and fell asleep. The next morning, however, he had no recollection of the preceding three days, except for an isolated memory of shopping on the day before the accident; the other two day were a complete blank. Since he was physically quite fit, with no other disability, he considered his work capacity to be as good as ever.

On November 9, 1963, he visited us with a complaint of tremor in his extremities, which had gradually spread after the accident. Neurological testing revealed a slight aggravation of deep tendon reflexes in the right half of his body, and psychological testing suggested a slight depressive mood and a preoccupation with the tremor but nothing else serious. The resting EEG was interpreted as normal, while the bemegride activated EEG revealed a paroxysmal cerebral dysfunction with a very minimal left temporal irritation. After several unsuccessful interviews, he was included in the hypnotic program on an outpatient basis. Additionally, an attempt was made to reduce the amnesias under the moderate or deep trance of a hypnotic state. He made a tremendous recovery in the program, and he remembered all the events of November 13,14, and 15, including where and how he had driven the car before the accident. Furthermore, he recalled the details of the accident and of the period immediately following. He had completely recovered from the RA and the PTA and also from the tremor in his extremities. In summary this patient had PTA for one day and RA for two days, both of which were subsequently abolished by hypnotic treatment.

Case $3:$ K. N., male, age 16, was thrown from his motorcycle as it crashed into a light car on June 30, 1964. According to the medical record, 40 minutes later he was able to converse sensibly and nursing staff considered him to be fully conscious. However, he seemed to have been partly cloudy until July 3, when he actually became fully conscious. In other words, he had PTA for two days. when questioned 25 days after the accident he had RA for three days in addition to the PTA. An EEG abnormality was induced by $10 \mathrm{mg}$ of bemegride; this was interpreted as a spike focus in the right fronto-central region. He 
remembered that he had been listening to music at home on June 28 and that a friend had asked for a ride on his new motorcycle just bofore the accident, but nothing more until he completely recovered consiousness.

With the cooperation of his family and friends, he was involved in suggestive treatment and was told over and over again what had happened to him during the three days. A week after the repeated attempt, he remembered events on June 27 to 30 , up to the moment of the accident. He no longer had RA, but the PTA remained and was scarcely reduded when he returned to work in September of 1964.

Case 4: A.T., male, age 23, was admitted to a hospital after having a motorcycle accident on September 12, 1961. He came to hours later. He had only a laceration the left cheek and no fracture on the $\mathrm{X}$-ray eyamination. Because he was so forgteful that he appeared retarded, he was transferred to our clinic on October 4, 1961.

When first examined he was disoriented and amnesic. The EEG revealed brain damage in the right hemisphere, particularly frontal, but there was no significant change on pneumoencephalogram and carotid angiogram. He was included in a routine care program in the ward. A month after admission, he recovered orientation in time and place and perseverance in memory. However, circumstances did not allow him to be included in an intensive treatment. He performed well on all intelligence tests, but had RA for 16 hours and PTA for five days. He was discharged in November 1961 and returned to work in January, 1962. He was very fit, but there was permanent amnesia as far as reported.

Case 5 : U.K., male, age 26, had a motorcycle accident while inebriated on September 1, 1965. He was unconscious for ten days, and there wad a basal fracture of the skull on the X-ray examination. When he came to he was unable to recognize his parents or to remember anything about his surroundings. When he visited our clinic with a complaint of right hemicrania and right facial paresis two months after the injury, he was alert and correctly oriented, but had RA for 18 hours which were a complete blank. He remembered everything before he had punched in the time recorder at job on August 31 and after he realized an inability to open his right eye on September 10 . Suggestive and hypnotic treatment was repeated on him to reduce the RA and the RTA, but without success. There was permanent amnesia.

Case $6: \mathrm{K}$.T., male, age 22 , was thrown from his motorcycle at a speed of $70 \sim 80 \mathrm{~km} / \mathrm{h}$ (45 50mph) around 0:30a. m. on July 6, 1964. He regained consciousness in our clinic 13 day after the accident. When first seen he was quite alert and very sensible, and there was no mental or physical abnormality. His memory of events before the accident was normal up to about five hours before the accident. He clearly remembered leaving work at $7: 30 \mathrm{p} . \mathrm{m}$. 
on July 5 , but he had no memory at all thereafter, except that he vaguely remembered checking the motorcycle at a filling station and shouting to his friends in a tunnel on the expressway. He was involved in an intensive treatment. After he retraced the same route he had driven on the night of the accident under a doctor's supervision, he remembered every detail of the events before the accident. The PTA was barely changed by the treatments.

Case 7 : J.K., male, age, left his job by bicycle at 3:00p. m. on September 21, 1964, to see a dentist at 4:00p. m. but he did not arrive back at work until a little before $5: 00 \mathrm{p} . \mathrm{m}$. Bruises and scratches covered the left half of his body. He was so absent-minded that he did not realize his condition until a co-worker noticed the wounds. Immediately he was taken to a surgeon, treated, and returned to the workshop. He ate supper around 6:00p.m., when he was hale and alert.

He was admitted to our clinic with a complaint of headache with nausea on October 14. When examined there was nothing particularly wrong either mentally or physically, except the RA and PTA for two hours. Since there was no witness to his accident, it was not clear how he had been injured but from the appearance of his wounds and of the street, he probably either fell on the pavement or crashed into a telegraph pole. His amnesia did not improve even after repeated treatments, including interviews with exercise, sodium amytal, and hypnosis.

Case 8: M.M., male, age 14, was hit by a commuter train at the platform on May 15, 1963. There was a depressed fracture of the skull in the right frontal region. He regained consciousness on May 29, four days after the injury. When first seen in our clinic he had RA for about four hours and PTA for three days, in addition to an EEG abnormality which was localized by part of the injury. His memory of events before the injury was normal up to lunch time on the day of the accident, but he had no memory at all of the events for the rest of that day or for three days after the injury. He was not included in the hypnotic treatment for some reason.

Case 9: T.S., male, age 22, police trainee, was thrown down while engaged in judo and hit the back of his head against a mat, around 5:00p. m. on December 17, 1963. At that time he complained only of feeling dizzy and went on with the exercise. Half an hours later he began to blurt out repeatedly, "Am like dreaming", "Left my cap behind", and so on. He was admitted to our ward early in the next morning. When first seen, he was slightly clouded and confused, and a squint eye with anisocolia was found. The EEG was low and lazy, and the cerebrospinal fluid was bloody. There was a suspicion of subdural bleeding. 
On December 20 he come to and had a consecutive memory of subsequent events. He remembered being awakened by an instructor at $6: 00 \mathrm{a} . \mathrm{m}$. on the day of the injury, but nothing more until around noon on December 19. His memory of his medical examinations such as EEG and lumbar puncture on admission remained vague and fragmentary. When questioned again two weeks after the injury, there was a PTA for three days and RA for 11 hours. He was included in a hypnotic program. Under moderate and deep trances he remembered events of the day of injury until about noon; the remembrance was associated with a furious emotion. Four attempts were made to restore the blank in his memory, but without success. Consequently the RA was shortened to five hours but the PTA was unchanged.

Case 10: K.M., male, age 17, student, fell on his back while being tackled in a rugby game on September 6, 1965. From the teammate's report, he rose to his feet one to two minutes later and kept on playing. When the game was over he began to complain of a headache and was taken to the dispensary to rest. When questioned by a teacher, he repeated only "I don't know". In the evening he was admitted to the emergency room of a hospital after becoming unconscious with nausea and vomiting. He came to around 3:00a.m. in the next morning.

When first seen two weeks after the accident he was quite alert and oriented except for an RA of four hours and PTA for 13 hours. He remembered up to the first period at school on the day of the injury, but he had no recollection of the following 13 hours. When reexamined on October 7 , no shortening of either amnesia was found, but he could not be included in the hypnotic treatment.

Case 11: A. Y., female, age 22, fell on her back while skating and was hit on the occiput on May 18, 1964. She regained consciousness two hours later; there was no external injury. She visited us with a complaint of headache, nausea and dizziness on July 7, 1964. The neurological examination revealed a pyramidal sign, and the bemegride-activated EEG produced an atypical spike wave complex. There was RA for over three hours and PTA for two hours. For thess five hours her memory was completely blank. She was not included in the hypnotic program. She returned to her work with no headache or nausea but with the amnesia unchanged, and she found her work capacity to be as good as ever.

Case 12 : F.S., female, age 36 , fell from a step stool and her head against a wooden floor on October 6, 1965. She became able to talk about ten minutes later but was quite confused. She fully regained consciousness seven hours after the accident. On October 30, she visited us with headache and irritation since the accident and amnesia from the day preceding it. When examined she was all right mentally and physically except for PTA for 
seven hours and RA for two days. She had an indistinct memory of the day of the accident but no recollection of the previous day. She remembered only two incidents on the day of the accident. By November 24 she recovered another island in the RA during which she was visited by her father around noon. Then she was involved in the hypnotic program on December 2.

Under deep trance she confessed that she had long been misconducting herself with a young man from her husband's store and because of a guilty conscience had no heart for her work. On the day of the accident, she was worried about being forced to have to hunt for an apartment for her lover, since he called her to press her make a date with him in the morning. In addition to the actual conflicts, she remembered every detail of events before the accident but none of those after the accident. There was a permanent PTA for seven hours.

Case 13: J. T., male, age 14, student, was seen on June 28, 1962 . A classmate found him being beaten up by senior students and stained with blood after school on June 25 . Either when he reached home or when returned again from night school, he blurted out "Where have I been?". The 20 hours from the first period of school on June 25 until the full recovery of his consciousness on June 26 were completely blank. There was an RA of about six hours and PTA for 14 hours. Several interviews were made without success. Under amytal interview, he remembered having a quarrel with the seniors in the morning, trembling in class with fear of their revenge, being taken to the roof and beaten up by them, but could not indicate the exact place where he was beaten. His blank memory for the following 14 hours remained unchanged.

\section{Discussion and Conclusion}

Of 13 patients with RA for over an hour, nine were found to have some substantial brain damage; in particular, five of them were suspected of having damage in the cerebral region where Hoening et al. located the so-called mnestic system ${ }^{3)}$. It is, however, not uncommon that many patients can be found completely free from RA in of having definite damage in that region of the brain. As a matter of course, the authors do not stand against nor deny the importance of cerebral localization in various disorders of remote and recent memory. Generally brain damage has a much greater effect on recent memory than on remote memory. As memories become older they become more strongly established irrespective of their importance to the individual, while recent memories are relatively liable to traumatic extinction, however important they may be. The actual involvement of the so-called mnemic system seems to be worthy of less consideration in cases of RA than in cases of PTA, because 
it cannot be the sole cause but only provides a basis for the incidence of RA in all respects.

The severity of the cerebral damage as its localization are important factors in producing amnesia. Based on the surgeon's records and the patient's report, the head injuries studied have been classified into four types which roughly suggest the severity of cerebral damage according to Araki's scale. Case 7, 10, 12 and 13 were type $\mathbb{I}$, case 9 was type $\mathbb{I}$, and the others were all type II as contusion of the brain. Generally, type I can be considered less severe than type II and $\mathbb{N}$. Neverthelese it must be remembered that many patients with type III injury never have RA. On other hand, despite Case 12's injury being classified as type $\mathbf{I}$, the RA was longer than in many cases of type $\mathbf{I}$ injury. The severity of the brain in a determining factor in the presence of RA, but by itself the severity is not sufficient to cause RA.

The authros are convinced that most RAs are not permanent but are reducible or sometimes abolishable in some way, while PTAs can scarcely be shortened by any means. The PTA is, as mentioned previously, a useful indication of severity. The relationship of PTA to RA also been discussed in comparison to Russell's figure. As far as head injury is concerned, RA is almost always associated with PTA but the reverse is not necessarily true. Therefore, it is clear that severity is related more to the PTA than to the RA. In cases of RA, much attention should be paid to other possible factors as well as to substantial damage to the brain.

Two passengers in Case 1 and four passengers in Case 2 were injured more or less seriously than the two drivers. It is noteworthy that none of the passengers ever presented any loss of remote memory. For instance, S. M., a passenger in G. A.'s car, who was critically wounded and has a permanent PTA of over two weeks, remembered the very moment of the disaster when he came to in the hospital. It is generally accepted that head injury is usually less frequent and less severe in the driver than in the passengers in traffic accidents.

Of 847 cases of head injury in the own experiences, 429 cases were involved in some kind of traffic accident; of these, 30 were drivers, 49 were passengers, 46 were cyclists, 147 were pedestrians, and 47 were miscellaneous. Nevertheless, of the 13 cases of marked RA in the 847 cases, none were passengers or pedestrians. It is not always true pedestrians are more innocent and less responsible for the accident than drivers or cyclists.

The incidence of $4.6 \%$ in cases of drivers, $2.2 \%$ in cases of cyclists, and $1.8 \%$ in the others is not statistically significant, but is sufficient to attach clinical importance to the result. A driver can not shirk his responsibility for an accident or shift it to others unless he is hit from the rear. Moreover, all the accidents in which the seven cases of RA were involved were obviously due to their own careless driving or reckless speeding. Usually a 
driver attempts to make a plausible excuse for an accident, but he cannot get by with that excuse. Case 8 was to blame for his absent-mindedness. Cases 9 through 12 could not blame any other person. Even Case 13 could not be considered an innocent victim. Consequently, all the incidences of head injury in our 13 patients were found to have been caused by their own failure, imprudence or recklessness, which should induce some degree of guilt feelings or regretfulness. Both Case 12 and Case 13 seem to have been predisposed mentally prior to the incident.

It is quite reasonable to suppose that they had an unconscious desire to escape from reality before their injury and refuse to associate memories which were unpleasant after the injury ${ }^{1)}$. In the three cases injured in sports, there was no evidence of their having been mentally predisposed as far as we knew. However, only one of them was included in the intensive treatment and the duration of the RA was reduced to only a half. Even these must have had feelings of self-reproach for their failures. Thus their RA can also be regarded as triggered by an emotional factor. The accident could be the events they would not like to remember.

Ohya, one of the authors, reported two cases of psychogenic amnesia which is known as psychogenic loss of personal identity and stressed defense mechanism of the depressive states in the breakout of amnesia in the depressive states after pent up conflicts from the circumstances and environments ${ }^{7)}$. He also reported another case of total amnesia who had presented an unusual course of recuperation from an alcohol induced loss of personal history. He did not forget to suggest the latent relevarence to functional disturbances of physiological mechanism even in the case of psychogenic amnesia ${ }^{6)}$.

However, two patients whose RAs were successfully treated by Fortanier and Kandou using the hypnotic method both had penetrating wounds due to gunshot ${ }^{2)}$. These cases were very unusual ones; one an unsuccessful suicide and the other a gunshot wound by brokenhearted man in a triangular love affair; and they should be considered as psychogenic amnesia in nature ${ }^{2)}$.

Nielsen reported a case of $\mathrm{RA}$ of over 26 years in a man who had an automobile accident on his way to court to move for his own bankruptcy5). This patient's RA was out of proportion to the severity of the injury suffered and had to be regarded as largely psychogenic. It is generally true that in cases involving medical and legal considerations the length of RA can hardly be reduced because a strongly positive attempt to associate memories is deliberately lacking in those cases as in the hysterical and malingering ones. Of our 13 cases, five had RA longer than PTA, two that were equal to the PTA and six that were shorter than the PTA. In most of them the psychological testing revealed some deviation in 
personality, tendency to depressive mood, and features of psychoneurosis, subclinically. It seems reasonable that the recuperation from memory loss was disturbed by an emotional or psychic factor closely related to the accidental injury in cases of marked RA without any permanent loss of intellectual capacity 1) 13).

Three of four cases with RA longer than PTA made a good recovery from the RA. All of the nine cases involved in intensive treatment no longer have RA not proportional to PTA. The loss of remote memory which exceeds the loss of recent memory can be interpreted as amnesia more or less influenced by underlying psychic factors such as feelings of regret, self reproach or guilty conscience, and can be expected to be reduced or sometimes abolished by intensive care using psychotherapeutic approach.

Four patients who were not included in the hypnotic program have not shown any improvement as far as memory disorder is concerned. Aside from them, there are two case who did not show any progress in spite of their having been included in the program. However, the authors have not found any positive reason for our failures in these cases. It may be due to not enough effort and enthusiasm on our part or due to the nature of their amnesia.

In Case 2 the hypnotic treatment abolished not only RA but also PTA, which is generally considered to be exclusively organic. He had no recollection of things he had done after the accident, while he had been able to converse and to behave quite sensibly. Since he could subsequently recall every detail of those events after the treatment, his memory of them must have been normally recorded but was unconsciously repressed for a reason similar to that in the case of RA. In this respect, the PTA in Case 2 is a little different from the PTA in the others. Nevertheless, it must be noted that the PTA is not always purely organic but occasionally psychogenic as seen in this case.

Based on the above observations and discussions, the authors have reached the following conclusions; 1) In amnesia due to head injury, either type of amnesia consists of at least two phases or aspects, namely physiological and psychological; 2) the physiological phase is ordinarily dependent on organic aspects of an injury while the psychological is due to psychogenic reactions of the whole personality to an incident; 3) PTA can be considered mostly physiological and RA as mainly psychological 4) ;most of RAs and some PTAs be reduced or sometimes abolished by some psychotherapeutic procedure.

\section{Summary}

The authors have studied the frequency of RA in 144 cases of PTA found in 847 cases of head injury in the records from 1959 to 1965. The difference between Russell's and our results may be due to the trivial difference of criteria for RA. Clinical observations of 13 
cases of RA for over an hour have also been presented with the outcome of memory loss after intensive treatment with suggestion, exercise, hypnosis and amytal interview. In cases of traffic accidents, all of our cases were found to have been responsible for their accidents, and in other accidents, to have had some ideas of self-reproach. The importance of psychic or emotional factors in the occurrence of RA and the necessity of intensive treatment by psychotherapy have been discussed.

\section{References}

1) Ables, M. and Shilder, P. : Psychogenic loss of personal identity (amnesia). Arch. Neurol. Psychiat., 34, 587 604, 1935.

2) Fortanier, A.H. and Kandou, T. A. : Aufklärung von Amnesie nach Kophtrauma. Z. ges. Neurolo. Psychiat., 156, 265 273, 1936.

3) Hoenig, J., Anderson, E.W., Kenna, J C. and Blunden, R. : Clinical and pathological aspects of the mnestic syndrome. J. ment. sci., 108, 541 559, 1962.

4) Hayashi, S. : Psychiatric approach to the problem of head injury (contusio cerebri). Psychiat. Neurol. Jap. , 69, 1195 1209, 1967.

5) Nielsen, J.M. : "Memory and amnesia". San Lucas Press, Los Angeles, 1956.

6) Ohya, D., Sakurai, A., Kishikawa, R., Ohya, M, and Kimura, S. : A case of total amnesia with specific clinical course. Seishin-Igaku (Clinical Psychiatry), 30, 1227 1229, 1988.

7) Ohya, D. : Two cases of psychogenic amnesia and the significance of their depressive states. J. Kansai Med. Univ., 598 605, 1985 (Japanese).

8) Russell, W. R. : Cerebral involvement in head injury. Brain, 55, 549 603, 1932.

9) Russell, W. R. : Amnesia following head injuries. Lancet, 2, 762 763, 1935.

10) Russell, W. R. : "Brain Memory Learning". Clarendon Press, London, 1969.

11) Russell, W.R. and Nathan, P.W. : Traumatic amnesia. Brain, 69, 280 300, 1964.

12) Sakaguchi, K. : Retrograde amnesia in traffic accidents. Seisin-Igaku (Clinical Psychiatry), 11, 967〜 973, 1969 (Japanese).

13) Sakaguchi, K. : Clinical study on retrograde amnesia in case of head injury. J. Kansai Med. Sch., 21, 470 486, 1969 (Japanese with English abstract).

14) Sakata, H. : Memory disorders in the neurophysiology. Rinsho Seishin-Igaku (Jap. J. Clin. Psychiat.), 17, 1315 1324, 1988 (Japanese with English abstract).

15) Smith, H. V. : Principles of clinical neurology. In "Year Book of Neurology and Neurosurgery". Year Book Medical Publisher, Chicago, 1965.

16) Symonds, C.: Disorders of memory. Brain, 89, 625 644, 1966.

17) Talland, G. : Amnesia, aworld without continuity. In "Readings in Psychology Today". CRM Books, Del Mar, 1969.

18) Verjaal, A. : Amnesie nach Trauma Captis. Z. ges. Neurol. Psychiat., 166, 221, 1939.

19) Wolberg, L. R. : Medical Hypnosis, Vol. I. Grune and Stratton, New York, 1948.

20) Yamadori, S. : Memory disturbance from the neuropsychological stand point; a selective disorder of semantic memory. Rinsho Seishin-igaku (Jap. J. Clin. Psychiat.), 17, 1299 1305, 1988. 